\title{
Twin Loss: The Annual Convention / Twin Research Reviews: Childhood Empathy; Hormone Replacement Therapy and Skeletal Muscle; Multiple Birth Conception in Older Women / Twins in the Media: Twins With Kidney Disease; A Pair of Poets; The Other Twins in the Metrodome
}

\author{
Nancy L. Segal \\ Department of Psychology, California State University, Fullerton, United States of America
}

\begin{abstract}
oss of a twin has been largely overlooked by bereavement counselors and clinicians. This particular type of Lloss is also poorly understood among the public. Consequently, some bereaved twins have established a unique organization, Twinless Twins Support Group International, for the purpose of sharing this traumatic life experience with one another. The present article reviews events from the annual convention of Twinless Twins, held in July 2009, in Denver, Colorado. Selected findings from research on twin loss are also presented. Next, twin research concerned with the origins and implications of empathy, hormone replacement therapy and multiple birth conception will be reviewed. This article concludes with summaries of real life stories of twins' kidney disease, literary talent and retirement festivities.
\end{abstract}

\section{Twin Loss: The Annual Convention}

The Twinless Twins Support Group International (TTSGI) was founded in 1984, by Dr. Raymond Brandt. Its annual conventions allow dozens of twins to share their life stories with those who fully understand the nature and level of their grief. Many TTSGI members have participated in the ongoing Fullerton Twin Loss Study, research that began at the University of Minnesota in 1985. Some twins from the Australian Twin Register have also taken part.

I was privileged to attend the July 2009 Twinless Twins Convention, held in Denver Colorado. This meeting drew dozens of bereaved twins and some parents of twins together for a weekend of important and memorable moments. Highlights from two events (the keynote address and twin testimo- nials) follow a selected sampling of research findings on twin loss.

\section{$\overline{\text { The Research }}$}

Two key findings have emerged from the extant research on twin loss (see Segal, 2000 and references therein). The first is that $M Z$ twins experience the loss somewhat more intensely than DZ twins, although there is considerable overlap - the loss experience may be just as devastating for some DZ twins. There is also evidence of less grief reduction over time for $\mathrm{MZ}$ than DZ twins, on average (Segal \& Ream, 1998). The second finding is that the loss of a twin (MZ or DZ) is associated with greater grief than the loss of any other relative, with the exception of a spouse. This makes sense in evolutionary terms - in the absence of a partner, one cannot transmit genes to future generations. At the proximal level, spouses are the people chosen to be lifelong companions. Interestingly, grief associated with spouse loss did not differ from grief associated with twin loss. Comparing the effects of twin loss versus spouse loss between surviving $\mathrm{MZ}$ and $\mathrm{DZ}$ twins would be revealing; however, my own sample of nearly 700 bereaved twins does not include sufficient numbers to support such an analysis. In addition, very few twins (fortunately!) have lost children, also precluding twin group analyses of such data.

Address for correspondence: Nancy L. Segal, Department of Psychology, California State University, Fullerton, CA 92834, USA. E-mail: nsegal@Exchange.FULLERTON.EDU 
Loss of a twin either before, or shortly after, birth can profoundly affect surviving twins. Biographies of wellknown figures, such as science fiction author Philip K. Dick (Sutin, 1989), and rock n'roll legend Elvis Presley (Guralnick, 1994), include references to the missing twin in childhood and adulthood. Joan Woodward (1997) has studied such cases, but additional research in this area is clearly wanting. A timely issue concerns the emotional responses of adult individuals whose co-twins were selectively terminated, following the successful implantation of multiple embryos. I am unaware that such research has been done.

Suicide survivors constitute a special subgroup of surviving twins. They are a valuable research group because they enhance understanding of the nature and origins of suicidal behavior. Segal \& Roy (2001) and Segal (in press) found a higher frequency of suicide attempts among $\mathrm{MZ}$ than DZ twins whose co-twins had suicided. They also found that suicide attempts occurred with very low frequency among both $\mathrm{MZ}$ and $\mathrm{DZ}$ twins whose co-twins' death were non-suicides. These results are consistent with genetic effects on suicidal behavior.

Tomassini et al. (2003) reported a reduction in suicide among both $\mathrm{MZ}$ and DZ Danish twins, relative to nontwins. The interpretation was that twins provide social support for one another, offsetting any risk. Rasulo et al. (2005) found that survival is improved by having a spouse, friends and a co-twin. Contact frequency was a significant factor in the survival of women and $M Z$ twins.

Finally, the coping process of some twin suicide survivors can be compli- cated because they cannot express anger at a person or event for causing their twin's death. This reaction was expressed by several twin suicide survivors at this year's Twinless Twins convention.

\section{The Convention}

The first address of the morning was by New York City clinical psychologist Mary Morgan. She was ideally qualified to do this, given her professional background and the fact that she lost her twin brother at the age of 21 . She mentioned the immediate connection she felt with the group when she first joined.

Several key themes were touched upon in her talk. One was the extreme loneliness that twins feel when they lose their co-twin. Everyday reminders (e.g., a song or a smell) can reawaken the fact that the twin is no longer present. Another theme was the uniqueness of each person's recovery process. People cope with their loss in individual ways and according to individual timetables. A final theme was the lack of understanding that some family members may unknowingly display toward bereaved twins. The process of recovery may take longer for twins than for non-twin relatives who can become impatient with twins' enduring grief. All these themes have emerged from the Twin Loss Surveys completed for the Fullerton Twin Loss Study.

Mary Morgan should be applauded for her efforts on behalf of the twin survivors of the World Trade Tower attack. With help from the wife of a surviving twin, she organized a support group for several of the New York City twins that lasted for months in the aftermath of that tragic event. Additional information about her work can be found at www.twinlesstwins.org. A biographical sketch of one such survivor is included in Indivisible by Two: Lives of Extraordinary Twins (Segal, 2007).

The second part of the day was dedicated to twin testimonials. Twins were invited to describe the circumstances of their loss, its effects on their life, their methods for coping and their fondest memories of their twins. These sessions were extremely moving and gave depth and substance to the data files that colleagues and I have amassed over the years. Each life story was a different take on the emotional difficulties and complexities that bereaved twins face. Teenagers mourned the fact that they would not experience this crucial life stage with their twin. Young adults worried about the wellbeing of their nieces and nephews (their co-twin's children). Older twins, even those whose twins had died many years before, emphasized the unreality of their loss. Many told me privately that one never fully recovers from the loss of a twin, which may explain why some twins return to the convention year after year. It was observed (ironically) that TTSGI's members are highly dedicated to the organization, even while they would prefer to be nonmembers.

Twin researchers are in the fortunate position of producing findings that are meaningful at both theoretical and applied levels. Closer personal contact between researchers and twins has enormous potential benefits for everyone. It can provide twins with information and guidance, and offer researchers ideas and topics for future study.

\section{Twin Research Reviews}

\section{Childhood Empathy}

The bases of empathic concern are of interest to developmental psychologists. A comprehensive study of empathy, using 122 3.5-year-old twin pairs from the Longitudinal Israeli Study of Twins, was reported by Knafo et al. (2009). The sample included $33 \mathrm{MZ}$ twin pairs, $49 \mathrm{DZ}$ same-sex twin pairs and $40 \mathrm{DZ}$ oppo- site-sex twin pairs. The study is comprehensive so methods and results will be summarized selectively.

Empathic concern was analyzed via videotapes of children's reactions to an examiner who pretended to hurt her knee. Their expressions of concern (as shown by facial, vocal and gestural-postural behaviors) were rated on a 0 (absent) to 3 (substantial concern) scale. Correlations for empathic concern were .25 for $\mathrm{MZ}$ twin pairs, .03 for DZ same-sex twin pairs and -.21 for DZ opposite-sex twin pairs, consistent with genetic influence. Model-fitting indicated heritabilities of .19-.30. Associations between empathic concern and hypothesis testing (behaviors in which children explored and/or tried to understand distress) were also explored in this study. 


\section{Hormone Replacement Therapy and Skeletal Muscle}

The physical effects of Hormone Replacement Therapy (HRT) have been controversial. A recent study used a co-twin control design to investigate the effects of HTR on skeletal muscle composition and function (Ronkainen et al., 2009). The sample included 15 MZ female twins pairs, discordant for HRT, who ranged in age from 54 to 62 years. HRT had been used by one member of the pair for an average of 6.9 years.

HRT users exceeded their twin sisters on the following measures: maximum walking speed, muscle power, thigh muscle cross-sectional area and relative muscle area. In contrast, relative fat area was smaller in HRT users. No significant co-twin differences were found in maximal isometric strengths or habitual walking speed. Eleven twins who had been placed on estrogen-containing substances showed decreased total body and thigh fat content, while four twins who had been placed on tibolone (a substance with estrogenic, androgenic and progestogenic effects) showed increased muscle areas. The investigators concluded that HRT offsets limitations in mobility and muscle weakness that can occur with aging.

\section{$\overline{\text { Multiple Birth Conception }}$ in Older Women}

Multiple pregnancies have increased over the last few decades, due largely to advances in artificial reproductive technology. Given that the egg quality of older women can be compromised, some women have sought eggs from younger donors. A recent study compared maternal and fetal outcomes of twins conceived by these older mothers ( $n=42$, age 49.2 years) with those of control mothers of twins ( $n=$ 417 , age 31.6 years) (Simchen et al., 2009). A third group of older women who had conceived non-twins via egg donation were also available for study.
The sample allowed for a number of informative group comparisons. Older mothers of twins showed increased rates of hypertension (50\%) and diabetes $(31 \%)$ during pregnancy, although these frequencies matched those for older mothers carrying nontwins who had also pursued ovum donation. A higher rate of these twin mothers required hospitalization during the pregnancy (69\%), relative to those carrying singletons (47\%).

In another set of analyses, earlier deliveries were more frequent among mothers who conceived twins via egg donation (35.2 weeks) than among younger twin mothers who had conceived twins naturally (35.7 weeks). The risk of delivering before 34 weeks was almost twice as high in the older group as the younger group. It was concluded that an aging uterus may lead to multifetal pregnancy complications, and that older women trying to become pregnant through ovum donation should try for singletons.

\section{Twins in the Media}

\section{Twins With Kidney Disease}

MZ twins, Zaira and Yessenia Segoviano, are concordant for kidney failure (Funes, 2009). Zaira was diagnosed with the condition at age fourteen when she experienced a series of seizures. Her co-twin has not shown symptoms, but has tested positive for the condition. Both twins now require constant medical care for survival, for example, peritoneal dialysis for 10 hours each night. Genetic factors appear to be implicated in kidney disease. In a study of diabetic individuals with and without kidney changes, pathology of the kidney in the proband was the only significant predictor of risk to diabetic siblings (Seaquist et al., 1989).

This summer, the twins will attend Teen Camp in Mammoth Lakes, sponsored by the National Kidney Foundation of Southern California. The camp emphasizes independence in treatment, as well as an opportunity for affected teenagers to meet others with the same medical problem.

\section{$\overline{\text { A Pair of Poets }}$}

The April 6th issue of the New Yorker magazine ran an intriguing biographical sketch of $\mathrm{MZ}$ twin poets, Michael and Matthew Dickman (Mead, 2009). Both twins' poetry reflects their experiences and observations in the rough Portland, Oregon neighborhood in which they grew up. However, their literary styles differ - Michael's writing includes verbal fragments, even one-word lines, while Matthew's includes effusive phrases and cultural references. Both twins have earned prizes for their poetry.

Mead (2009) asserts that these twins (who were raised together) offer an experiment that is 'parallel' to that of MZ twins reared apart. She reasons that Matthew and Michael show the 'distinctiveness of imagination' (p. 44) in two people who are as similar as any two people can be. It is implied that identical twins reared apart may be similar because they are unaffected by one other, whereas identical twins raised together attempt to differentiate.
This could be true in individual cases and for some traits, although research shows that $\mathrm{MZ}$ twins reared apart and together show the same level of personality similarity (Tellegen et al., 1988). We can only wonder how similar the writings of these two poets might have been had they been reared apart. The original article is well worth reading.

\section{The Other Twins in the Metrodome}

An abundant literature provides evidence of genetic influence on vocational interests (Betsworth et al., 1994) and work values (Keller et al., 1992). Twins' real life stories offer a close-up look at such data. MZ twins, Rich and Ron Patnode, have both worked in construction at the Twin Cities Metrodome, home of the Minnesota Twins. They recently retired after having been associated with the same company for thirty years, and with the same union for 40 years. The twins plan to build retirement homes next to one another, and to pursue their shared interests in golfing and fishing. 


\section{References}

Betsworth, D. G., Bouchard, T. J., Jr., Cooper, C. R., Grotevant, H. D., Hansen, J. I. C., Scarr, S., \& Weinberg, R. A. (1994). Genetic and environmental influences on vocational interests assessed using adoptive and biological families and twins reared apart and together. Journal of Vocational Behavior, 44, 263-278.

Funes, J. (2009, June 24). Twin Sisters Can Share Park Time. Los Angeles Times, p. D-2.

Guralnick., P. (1994). Last train to Memphis: The rise of Elvis Presley. Boston: Little Brown and Company.

Keller, L. M., Bouchard, T. J. Jr., Arvey, R. D., Segal, N. L., \& Dawes, R. V. (1992). Work values: Genetic and environmental influences. Journal of Applied Psychology, 77, 79-88.

Knafo, A., Zahn-Waxler,C., Davidov, M., Van Hulle, C., Robinson, J. L., \& Rhee, S. H. (2009). Empathy in early childhood: Genetic, environmental and affective contributions. Annals of the New York Academy of Sciences, 1167, 103-114.

Mead, R. (2009, April 6). Couplet: A tale of twin poets. The New Yorker, pp. 4249.
Rasulo, D., Christense, K., \& Tomassini, C. (2005). The influence of social relations on mortality in later life. A study of elderly Danish twins. Gerontologist, 45, 601-608.

Ronkainen, P. H. A., Kovanen, V., Alen, M., Pollanen, E., Palonen, E. -M., Ankarberg-Lindgren, C., Hämäläinen, E., Turpeinen, U., Kujala, U. M., Puolakka, J., Kaprio, J., \& Sipilä, S. (2009). Postmenopausal hormone replacement therapy modifies skeletal muscle composition and function: A study with monozygotic twins. Journal of Applied Physiology, 107, 25-33.

Seaquist, E. R., Goetz, F. C., Rich, S., \& Barbosa, J. (1989). Familial clustering of diabetic kidney disease. Evidence for genetic susceptibility to diabetic nephropathy. New England Journal of Medicine, 321, 905-906.

Segal, N. L. (2000). Entwined lives: Twins and what they tell us about human behavior. New York: Plume.

Segal, N. L. (2007). Indivisible by two: Lives of extraordinary twins. Cambridge, MA: Harvard University Press.

Segal, N. L. (In press). Suicidal ideation and suicide attempts in surviving $M Z$ and DZ co-twins. Suicide and LifeThreatening Behavior.

Segal, N. L., \& Ream, S. L. (1998). Decrease in grief intensity for deceased twin and non-twin relatives: An evolutionary perspective. Personality and Individual Differences, 25, 317-325.

Segal, N. L., \& Roy, A. (2001). Suicidal attempts and ideation in twins whose co-twins' deaths were non-suicides: Replication and elaboration. Personality and Individual Differences, 31, 445452.

Simchen, M. J., Shulman, A., Wiser, A., Zilberberg, E., \& Schiff, E. (2009). The aged uterus: Multifetal pregnancy outcome after ovum donation in older women. Human Reproduction, doi: 10.1093/humrep/dep238.

Sutin, L. (1989). Divine invasions: A life of Philip K. Dick. New York: Harmony Books.

Tellegen, A., Lykken, D. T., Bouchard, T. J., Jr., Wilcox, K., Segal, N. L. \& Rich, S. (1988). Personality similarity in twins reared apart and together. Journal of Personality and Social Psychology, 54, 1031-1039.

Tomassini, C., Juel, K., Holm, N. V., Skytthe, A., \& Christensen, K. (2003). Risk of suicide in twins: 51 -year follow-up study. British Medical Journal, 327, 373-374.

Woodward, J. (1997). The lone twin. London: Free Association Books. 